\title{
NADPH Oxidase Activity in Retinal Pigmented Epithelium as a Target for Prevention of Age- related Macular Degeneration
}

Author:

Mark F. McCarty

Catalytic Longevity, 7831 Rush Rose Dr., Apt. 316, Carlsbad, CA 92009, USA

Phone: 760-216-7272; Fax: 760-704-6379;

Email: markfmccarty@gmail.com

\section{Conflicts of Interest:}

The author is co-inventor and co-owner of a U.S. patent covering nutraceutical uses of phycocyanobilin-enriched spirulina extracts

\begin{abstract}
Considerable evidence points to macular oxidative stress as a key driver of age-related macular degeneration (AMD). In particular, retinal pigmented epithelial (RPE) cells subjected to oxidative stress are prone to apoptosis or senescence; lose their tight junctions; decrease their production of factors which provide trophic support for retinal photoreceptors, suppress choroidal neovascularization, and control complement activation; and boost their production of vascular endothelial growth factor (VEGF), a major stimulant to neovascularization - all effects which are consistent with the pathogenesis of AMD. There is good reason to suspect that NADPH oxidase activity in RPE cells is the key source of the oxidative stress that compromises RPE function in AMD. Studies with other cell lines indicate that a number of risk factors for AMD - including cigarette smoke, homocysteine, hyperglycemia, cadmium, and up-regulated activation of the alternative complement cascade - have the ability to stimulate NADPH oxidase activity, as does alltrans-retinal, a suspected pathogenic factor in AMD. Hence, measures which can downregulate NADPH oxidase activity may have potential for preventing or controlling AMD. These may include high-dose statins - found to reverse features of early AMD in about half of patients in a recent pilot study - and spirulina, a rich source of the chromophore phycocyanobilin (PhyCB ). PhyCB is a biliverdin derivative that can mimic the intracellular physiological role of bilirubin as an NADPH oxidase inhibitor. Patients with Gilbert syndrome or relatively high plasma unconjugated bilirubin may be at lower risk for AMD owing to bilirubin's inhibitory impact on NADPH oxidase; this prediction could be readily tested in epidemiological studies.
\end{abstract}




\section{NADPH Oxidase Activity in Retinal Pigmented Epithelium as a Target for Prevention of Age- related Macular Degeneration}

\section{Pathophysiology of AMD}

Age-related macular degeneration (AMD)is the leading cause of vision loss and partial blindness among elderly Americans 60 and older. ${ }^{1}$ The National Eye Institute estimates that there are presently about 1.75 million people in the U.S. with advanced AMD and associated vision loss. The number is expected to grow to approximately 3 million by 2020.Men and women are about equally affected, and the incidence of AMD in blacks is lower than it is in whites.AMD is the most common cause of visual impairment in the developed world.

AMD is a degenerative disease of the macula, the part of the retina responsible for the sharp central vision needed to read or drive; central vision loss is likely to occur. AMD may be manifested as a sudden worsening and distortion of central vision and may progress rapidly with a course of only weeks or months. Typically, AMD has a preclinical, asymptomatic phase, in which extracellular waste material known as "drusen" accumulates in the space between the basement membrane--Bruch's membrane-and the pigmented epithelial layer (comprised of retinal pigmented epithelial cells - RPE).

RPE cells are remarkably versatile in their contribution to healthful retinal function, and it is generally believed that dysfunction or death of these cells is crucial to AMD pathogenesis. The retinal pigmented epithelium serves as the blood-retinal barrier, and regulates the transport of oxygen, substrates and waste products between the choroidal vasculature and the retina. Loss of RPE tight junctions - which evidently compromises this barrier function - is a hallmark of AMD. RPE cells also generate growth factors that aid the survival of retinal photoreceptors and other cellular constituents of the inner retina, while suppressing pathological choroidal neovascularization.

The most curious function of RPE cells is to phagocytize photoreceptor outer segments
(POS). While doing this, they isomerize alltrans retinyl esters derived from POS back to 11cis-retinal, which is then returned to the photoreceptors for use in rhodopsin synthesis; this is a crucial function, as photoreceptors are incapable of performing this isomerization themselves. The phagocytic function of RPE cells entails continual lysosomal activity; when this activity is sub-optimally efficient, as it appears to be in AMD, lipofuscin deposits accumulate in these cells. Lipofuscin has photosensitizing activity, and components of lipofuscin - notably A2-E, a retinoid metabolite - can impair lysosomal function, in part by blocking the proton pump that acidifies lysosomes. (This raises the specter of a vicious cycle in which lipofuscin accumulation encourages further accumulation of lipofuscin). Proteomic studies indicate that the drusen that characterizes AMD is derived largely from inadequately degraded POS components as well as lysosomal proteins - suggesting that stressed RPE cells are disgorging half-digested lysosomal contents into the sub-epithelial space. ${ }^{2}$ Drusen is also rich in complement metabolites; this accords well with the discovery that AMD is more common in individuals who carry reduced-function alleles of key proteins that regulate the complement cascades. ${ }^{3}$

Degeneration of the RPE is considered the most important hallmark of AMD. This is characterized by pigment mottling, accumulation of intercellular lysosomal lipofuscin and extracellular drusen, loss of tight junctions, and apoptotic cell death. As discussed below, chronic oxidative stress isstrongly linked to RPE senescence and the pathogenesis of AMD .

Advanced forms of AMD include both dry (geographic atrophy) and wet (neovascular) AMD. The dry form of AMD is far more common, but the wet form occurs together with the dry form in about $15 \%$ of cases. Dry AMD is characterized by progressive apoptosis within the light-sensitive retinal macula, required for 


\section{NADPH Oxidase Activity in Retinal Pigmented Epithelium as a Target for Prevention of Age- related Macular Degeneration}

fine vision; apoptotic loss of photoreceptors, RPE cells, and the underlying cells in the choroidal capillary layer is noted. Wet AMD is characterized by choroidal neovascularization, with vascular leakage into subretinal spaces, and can lead to sudden, catastrophic, and permanent visual loss.

Subjects with a family history of AMD, smokers, and people who are obese or sedentary are at increased risk for this syndrome. People who are genetically prone to increased activation of the alternative complement pathway - such as those carrying certain alleles of the gene for complement factor $\mathrm{H}$ - are at greatly increased risk, perhaps reflecting a role for complement in drusen formation. ${ }^{4,5}$

\section{Oxidative Stress Plays a Key Role in the Pathogenesis of AMD}

Although the pathogenesis of AMD remains murky, there is a growing consensus that oxidative stress plays a key role in driving this syndrome. ${ }^{6-8} \quad$ Chemical markers of oxidative stress have consistently been found to be elevated in the maculas of patients with AMD. ${ }^{9}$ In cell culture studies, exposure of RPE cells to oxidative stress has been shown to impair the function and survival of these cells - inducing a loss of tight junctions, impairing production of pigmented epithelium-derived factor (PEDF - a growth factor that provides trophic support for photoreceptors while inhibiting choroidal neovascularization) and of complement factor $\mathrm{H}$ (impaired function of which has been linked to increased AMD risk ${ }^{3,10}$ ), boosting expression of vascular endothelial growth factor (VEGF - a key driver of angiogenesis), and promoting apoptosis and/or senescence- effects that are all consistent with the pathology of AMD. ${ }^{11-17}$ The oxidant-induced shift in the balance of PEDF and VEGF production in RPE cells seems likely to be a key mediator of choroidal neovascularization. ${ }^{15}$ Moreover, oxidative stress can also induce apoptosis in photoreceptors, an effect which seems likely to contribute to the photoreceptor loss characteristic of dry AMD. ${ }^{18}$ And the most well characterized risk factor for AMD is cigarette smoking, which is well known to promote oxidative stress in tissues; ${ }^{19-22}$ in mice exposed chronically to cigarette smoke, increased oxidative stress and apoptosis is noted in RPE cells, accompanied by thickening of Bruch's membrane. $^{22}$

A further line of evidence implicating oxidative stress in AMD is the fact that transgenic mice lacking superoxide dismutase activity have been shown to develop a syndrome very analogous to AMD as they age; drusen, thickened Bruch's membrane, and choroidal neovascularization are all observed, and the junctions linking retinal pigment endothelium are disrupted - features characteristic of human AMD. ${ }^{23}$ Increased light exposure accelerates accumulation of drusen in these mice, presumably because light promotes retinal oxidative stress.

Clearly, some of the oxidative stress that contributes to AMD pathogenesis results from light exposure. The macula is exposed to blue light that generates singlet oxygen and other reactive oxygen species when it interacts with photosensitizing chemicals; the lipofuscin that accumulates in stressed RPE cells is rich in such photosensitizers, some of which, such as A2-E, are derived from all-trans-retinal. ${ }^{24-26}$

Photoreceptors are exceptionally susceptible to oxidative damage, as their membranes are extremely rich in the long-chain omega-3 polyunsaturate docosahexaenoic acid (DHA); DHA can constitute up to half of the fatty acids in photoreceptor outer segments (POS). ${ }^{27}$ This presumably explains why POS membranes are also unusually rich in xanthophyll carotenoids capable of quenching the singlet oxygen that otherwise might peroxidize DHA. ${ }^{18}$, ${ }^{28}$ Thesexanthophylls also are found in photoreceptor axons, where their presumed key function is to absorb blue light before it can 


\section{NADPH Oxidase Activity in Retinal Pigmented Epithelium as a Target for Prevention of Age- related Macular Degeneration}

penetrate to deeper levels of the macula and generate oxidants. The fact that the xanthophyll content of the macula is subnormal in patients with AMD might in some measure be a consequence of the disease, but it is also reasonable to suspect that this deficit contributes to disease progression by lessening the macula's antioxidant protection. ${ }^{29-31}$

\section{NADPH Oxidase - A Key Source of Pathogenic Oxidative Stress in AMD}

There is good reason to suspect that NADPH oxidase may be a key source of oxidant stress in RPE cells. RPE cells act as phagocytes, engulfing outer segments of retinal rod photoreceptors; like other phagocytes, RPE possess NADPH activity that increases during phagocytosis. $^{32,33}$ More recent work establishes that RPE expresses p22phox, a key membrane component of NADPH oxidase complexes. ${ }^{34}$ Intriguingly, viral delivery of small interfering RNA for p22phox to the subretinal space prevents choroidal neovascularization in a mouse model of AMD (involving laser disruption of Bruch's membrane). ${ }^{35}$ The authors conclude that "NADPH oxidase-mediated ROS production in RPE cells may play an important role in the genesis of neovascular AMD, and this pathway may represent a new target for therapeutic intervention in AMD.” In addition, NAPDH oxidase activity is expressed by retinal neurons; this activity increases when growth factor support is withdrawn (as might be expected if death or dysfunction of retinal pigment epithelium impairs its trophic function), and there is suggestive evidence that NADPH oxidase activation may drive the apoptotic death of cone cells in retinitis pigmentosa. ${ }^{36,37}$

At least 5 risk factors for AMD - cigarette smoke, homocysteine, hyperglycemia, cadmium, and up-regulated activation of the alternative complement cascade - have the potential to activate NADPH oxidase in RPE cells, as documented below. Hence, a case can be made that up-regulated activity of NADPH oxidase in RPE cells plays a key role in driving the AMD syndrome.

Cigarette Smoke - Cigarette smoking is one of the best established risk factors for AMD, and the most important of the modifiable risk factors. ${ }^{38}$ The highly active oxidants in inhaled smoke that are traumatic to the lungs are unlikely to mediate this risk, as their half-lives are very short. However, cigarette smoke extract (CSE) also contains a range of more stable compounds capable of exerting systemic effects, including agents such as acrolein that can react with sulfhydryl groups in proteins via Michael additions. In cell culture studies, CSE has been shown to activate NADPH oxidase in a range of cell types; this activation, in turn, stems from activation of classical isoforms of protein kinase $\mathrm{C}$ (PKC). ${ }^{39-43}$ Acrolein and methyl vinyl ketone, prominent components of CSE, have been found to be particularly active in this regard. ${ }^{43}$ While exposure to RPE cells to CSE has been shown to evoke oxidative stress, studies examining the role of NADPH oxidase in this regard have not been published; nonetheless, results in other cell lines are consistent with the possibility that NADPH oxidase is a key source of oxidative stress in CSE-exposed RPE cells.

Homocysteine - Considerable epidemiology, both prospective and case-control, has associated modest elevations of plasma homocysteine with increased risk for AMD - as confirmed in a recent meta-analysis. ${ }^{44}$ Moreover, there is reason to suspect that this association is causal. The Women's Antioxidant and Folic Acid Cardiovascular Study (WAFACS) randomized 5,442 women at high cardiovascular risk (with pre-existing cardiovascular disease or with 3 or more cardiovascular risk factors) to a receive a supplement providing $2.5 \mathrm{mg}$ folic acid, $50 \mathrm{mg}$ pyridoxine, and $1 \mathrm{mg}$ cyanocobalamin, or matching placebo. ${ }^{45}$ 5,205 of these women did not have a diagnosis of AMD at baseline. Although the primary intent 


\section{NADPH Oxidase Activity in Retinal Pigmented Epithelium as a Target for Prevention of Age- related Macular Degeneration}

of this study was to examine the impact of homocysteine-lowering supplementation on cardiovascular risk, the authors prospectively decided to include assessment of new AMD incidence in their protocol. During an average follow-up of 7.3 years, the participants reported 55 new cases of AMD in the supplemented group and 82 in the placebo group (RR 0.66; CI: 0.47-0.93; $\mathrm{P}=0.02$ ); visually significant new AMD was reported by 26 subjects in the treated group, vs. 44 in the placebo group (RR 0.59; CI: 0.36-.095; $\mathrm{P}=0.3$ ). A sub-group analysis indicated that homocysteine levels fell by an average of $18 \%$ in the treated group, and the authors suggested that this may have contributed to the observed benefit.

The vascular toxicity of hyperhomocysteinemia is suspected to reflect induction of oxidative stress in the vascular system. Homocysteine has been shown to activate NADPH oxidase in vascular endothelium, and this effect likewise appears to reflect activation of PKC. ${ }^{46,}{ }^{47}$ Homocysteine thiolactone, a cyclic derivative of homocysteine produced by enzymatic activity within cells, reacts readily with protein lysine groups, and seems likely to be the true mediator of this effect. ${ }^{48}$ It is curious that, whereas folate supplementation has not been found to confer protection from myocardial infarction in subjects with moderately elevated homocysteine levels, it has been found to decrease risk for ischemic stroke $;^{49-51}$ this possibly reflects the fact that expression of NADPH oxidase is far higher in the cerebral vasculature than in other vascular beds. $^{52}$

Hyperglycemia - Both diabetes and frequent consumption of high-glycemic-index foods have emerged as risk factors for AMD is some though not all pertinent studies. ${ }^{53-55}$ Hyperglycemia induces oxidative stress in RPE cells and in the retinas of diabetic mice. ${ }^{56}$ Hyperglycemia has been shown to induce NADPH oxidase activation in a number of cell types, and, once again, PKC activation contributes to this effect. $^{57-60}$ Indeed, there is reason to suspect that activation of NAPDH oxidase is a key mediator of the complications of diabetes. ${ }^{61-64}$ Presumably, episodic elevations of plasma glucose associated with high-glycemic-index meals likewise could modestly boost NADPH oxidase activity.

Cadmium - Non-occupational cadmium exposure has been linked to increased risk for vascular diseases, various cancers, osteoporosis, nephropathy, and other disorders. ${ }^{65-68}$ The broad risks associated with high-normal body cadmium levels may reflect the ability of this toxic metal to promote oxidative stress. ${ }^{69-72}$ In particular, a number of cell culture studies point to NADPH oxidase as the source of this oxidative stress. ${ }^{73-78}$ In light of these considerations, it should not come as a surprise that recent epidemiological studies have linked high-normal levels of cadmium in urine, blood, or vitreous fluid to increased risk for AMD. ${ }^{79-84}$ In light of the fact that high-dose supplemental zinc can function as a cadmium antagonistvia induction of metallothionein, an antioxidant protein that alleviates cadmium toxicity by sequestering it, the favorable impact of highdose zinc (80 mg daily) on progression of AMD in the Age-Related Eye Disease Study 1 (AREDS1) might be attributable in part to cadmium antagonism. ${ }^{85}$ (Of particular interest is the fact that subjects enrolled in the zincsupplementation arm of this study also enjoyed a significant $27 \%$ reduction in total mortality rate, relative to subjects not receiving zinc, during the median follow-up of 6.5 years; could this reflect the broader pathogenic role of cadmium? ${ }^{68,86}$ )

Complement Cascade - Recent research may help to rationalize the high risk for AMD in people who express alleles of genes for complement factors or complement regulatory factors that would tend to up-regulate activation of the alternative complement pathway. ${ }^{3}$ Oxidative stress in RPE cells suppresses their production of cell-surface complement inhibitors, increasing risk for alternative 


\section{NADPH Oxidase Activity in Retinal Pigmented Epithelium as a Target for Prevention of Age- related Macular Degeneration}

pathway activation on the membranes of these cells $;{ }^{87}$ such activation should be most intense in those with low activity alleles of complement factor $\mathrm{H}$, an inhibitor of the alternative pathway. Activation of the alternative complement cascade in the microenvironment of the RPE likely explains why complement metabolites are found in drusen. ${ }^{3}$ Moreover, ARPE-19 cells have been found to express receptors for the proinflammatory complement metabolites C3a and $\mathrm{C} 5 \mathrm{a}$; activation of the $\mathrm{C} 5 \mathrm{a}$ receptor promotes production of the key angiogeneic factor VEGF. ${ }^{88}$ When RPE cells are exposed simultaneously to oxidative stress and serum, they produce VEGF; this effect is blocked if the cells are concurrently exposed to an alternative pathway inhibitor. ${ }^{87}$ Exposure of oxidatively stressed RPE cells to serum likewise potentiates their loss of tight junctions - an effect that again is suppressed by an alternative pathway inhibitor. Although the impact of C5a on NAPDH oxidase activity in RPE cells has not yet been reported, C5a has been shown to stimulate this activity, in macrophages, neutrophils, and eosinophils. ${ }^{89-92}$

All-Trans-Retinal - The extent to which impaired metabolism of all-trans-retinal (atRAL) might contribute to the pathogenesis of AMD remains unclear. atRAL is capable of activating NADPH oxidase in RPE cells as well as in photoreceptors by triggering the activation of receptors coupled to heterotrimeric $\mathrm{G}$ proteins. ${ }^{93-}$ ${ }^{95}$ Indeed, atRAL may mediate the toxicity of severe light exposure to photoreceptors by activating NAPDH oxidase;photoreceptorspecific knock-out of Rac1 in rod photoreceptors markedly protects them from light toxicity. ${ }^{96}$ The NADPH oxidase inhibitor apocynin is likewise protective in this regard. ${ }^{96} \mathrm{After}$ atRAL is generated by rhodopsin light absorption within photoreceptor discs, the Abca4 ATP-binding cassette transporter is required for atRAL removal from photoreceptor discs and its subsequent reductive metabolism; genetic variants of this transporter have been linked to increased risk for AMD, suggesting that increased delivery of atRAL to RPE cells via phagocytosis of photoreceptor outer segments can exacerbate the AMD syndrome. ${ }^{97}$

\section{Down-Regulating NADPH Oxidase Activity as a Strategy for Preventing/Controlling AMD}

High-dose lipophilic statins have the potential to down-regulate NAPDH oxidase activity by suppressing isoprenylation of Rac1, a step required for full activation of certain isoforms of NADPH oxidase. ${ }^{98-101}$ Hence, if NADPH oxidase activity in RPE cells plays a key role in the pathogenesis of AMD, one would expect that clinical or epidemiological studies would observe lower risk for AMD, or slower progression of the disorder, in patients receiving high-dose statins for vascular protection. Studies examining risk for or progression of AMD in statin users have observed inconsistent results, but arguably this could reflect the fact that statin doses achieving adequate control of blood lipids may be insufficient to influence NADPH oxidase activity. ${ }^{102-104} \mathrm{An}$ open pilot trial of highdose atorvastatin (80 mg daily) in AMD was initiated following the observation that, within 6 months of increasing his atorvastatin dose to 80 mg, an AMD patient experienced complete disappearance of drusen and an improvement in visual acuity by 12 letters. ${ }^{105}$ Twenty-three patients with prominent drusen deposits whose AMD had not yet progressed to geographic atrophy or choroidal neovascularization were recruited and treated for one year. In ten of the patients, drusen deposits decreased, and in 8 of these drusen virtually disappeared. These responding patients averaged a 3 letter gain in visual acuity. None of the patients in the trial progressed to neovascular AMD. Response did not correlate with extent of cholesterol reduction. These findings suggest that a properly controlled study of this regimen would be warranted. 


\section{NADPH Oxidase Activity in Retinal Pigmented Epithelium as a Target for Prevention of Age- related Macular Degeneration}

An alternative possibility for down-regulating NADPH oxidase activity is suggested by the discoveries that that intracellular free bilirubin functions intracellularly as an inhibitor of NAPDH oxidase ${ }^{106-108}$ (thereby rationalizing the antioxidant activity of heme oxygenase), and that phycocyanobilin (PhyCB), a bilirubin homolog that functions as a chromophore in spirulina and other microalgae, can mimic this activity. ${ }^{109,} 110 \quad$ Since orally administered spirulina or phycocyanin - the spirulina protein which contains PhyCB as a chromophore exerts neuroprotective effects in rodent studies, and parenterally administered phycocyanin or PhyCB is highly protective in rodent stroke models, there is reason to suspect that spirulina or PhyCB-enriched spirulina extracts may have the potential to confer antioxidant protection to the retina. ${ }^{111-114}$ So far, however, no studies have examined the impact of spirulina or phycocyanin on retinal function or pathology. It would be of particular interest to determine whether individuals with Gilbert syndrome - an innocuous genetic variant associated with chronically elevated plasma levels of unconjugated bilirubin and reduced risk for cardiovascular disease ${ }^{115}$ - are at decreased risk for AMD. More generally, do plasma levels of unconjugated bilirubin correlate inversely with risk for AMD in prospective cohorts?

\section{Overview}

Current nutraceutical/pharmaceutical strategies for preventing or impeding the progression of AMD, as suggested by controlled clinical trials high-dose zinc, antioxidant vitamins, xanthophylls, DHA, folate/B12 - are worthwhile, but fail to stop progression of the syndrome in a high proportion of patients. The evidence presented above strongly suggests that activation of NADPH oxidase in RPE cells may play a key pathogenic role in AMD, and hence that effective targeting of NADPH oxidase might enable a further advance in management of this disorder. Further controlled evaluation of high-dose lipophilic statins in AMD appears warranted. In regard to the possible utility of spirulina in this regard, the absence of a rodent model of AMD makes it difficult to evaluate this potential pre-clinically. Once PhyCB-enriched spirulina extracts are available as nutraceuticals, open label pilot studies could be attempted to ascertain whether these extracts appeared to have any evident impact on progression of AMD. If these preliminary efforts yielded encouraging observations, double-blind trials would then be appropriate. 


\section{NADPH Oxidase Activity in Retinal Pigmented Epithelium as a Target for Prevention of Age- related Macular Degeneration}

References

(1) de Jong PT. Age-related macular degeneration. $N$ Engl $J$ Med 2006 October 5;355(14):1474-85.

(2) Wang AL, Lukas TJ, Yuan M, Du N, Tso MO, Neufeld AH. Autophagy, exosomes and drusen formation in agerelated macular degeneration. Autophagy 2009 May;5(4):563-4.

(3) Anderson DH, Radeke MJ, Gallo NB et al. The pivotal role of the complement system in aging and age-related macular degeneration: hypothesis re-visited. Prog Retin Eye Res 2010 March;29(2):95-112.

(4) Despriet DD, Klaver CC, Witteman JC et al. Complement factor $\mathrm{H}$ polymorphism, complement activators, and risk of age-related macular degeneration. JAMA 2006 July 19;296(3):301-9.

(5) Despriet DD, van Duijn CM, Oostra BA et al. Complement component C3 and risk of age-related macular degeneration. Ophthalmology 2009 March;116(3):474-80.

(6) Beatty S, Koh H, Phil M, Henson D, Boulton $\mathrm{M}$. The role of oxidative stress in the pathogenesis of age-related macular degeneration. Surv Ophthalmol 2000 September;45(2):115-34.

(7) Beatty S, Koh H, Phil M, Henson D, Boulton $\mathrm{M}$. The role of oxidative stress in the pathogenesis of age-related macular degeneration. Surv Ophthalmol 2000 September;45(2):115-34.

(8) Cai J, Nelson KC, Wu M, Sternberg P, Jr., Jones DP. Oxidative damage and protection of the RPE. Prog Retin Eye Res 2000 March;19(2):205-21.

(9) Shen JK, Dong A, Hackett SF, Bell WR, Green WR, Campochiaro PA. Oxidative damage in age-related macular degeneration. Histol Histopathol 2007 December;22(12):1301-8.
(10) Donoso LA, Vrabec T, Kuivaniemi H. The role of complement Factor $\mathrm{H}$ in age-related macular degeneration: a review. Surv Ophthalmol 2010 May;55(3):227-46.

(11) Bailey TA, Kanuga N, Romero IA, Greenwood J, Luthert PJ, Cheetham ME. Oxidative stress affects the junctional integrity of retinal pigment epithelial cells. Invest Ophthalmol Vis Sci 2004 February;45(2):675-84.

(12) Ohno-Matsui K, Morita I, TombranTink $\mathrm{J}$ et al. Novel mechanism for agerelated macular degeneration: an equilibrium shift between the angiogenesis factors VEGF and PEDF. $J$ Cell Physiol 2001 December;189(3):323-33.

(13) Wu Z, Lauer TW, Sick A, Hackett SF, Campochiaro PA. Oxidative stress modulates complement factor $\mathrm{H}$ expression in retinal pigmented epithelial cells by acetylation of FOXO3. J Biol Chem 2007 August 3;282(31):22414-25.

(14) Kasahara E, Lin LR, Ho YS, Reddy VN. SOD2 protects against oxidationinduced apoptosis in mouse retinal pigment epithelium: implications for age-related macular degeneration. Invest Ophthalmol Vis Sci 2005 September;46(9):3426-34.

(15) Ohno-Matsui K, Morita I, TombranTink J et al. Novel mechanism for agerelated macular degeneration: an equilibrium shift between the angiogenesis factors VEGF and PEDF. $J$ Cell Physiol 2001 December;189(3):323-33.

(16) Kannan R, ZHANG N, Sreekumar PG et al. Stimulation of apical and basolateral VEGF-A and VEGF-C secretion by oxidative stress in polarized retinal pigment epithelial cells. Mol Vis 2006;12:1649-59. 


\section{NADPH Oxidase Activity in Retinal Pigmented Epithelium as a Target for Prevention of Age- related Macular Degeneration}

(17) Marazita MC, Dugour A, MarquioniRamella MD, Figueroa JM, Suburo AM. Oxidative stress-induced premature senescence dysregulates VEGF and $\mathrm{CFH}$ expression in retinal pigment epithelial cells: Implications for Agerelated Macular Degeneration. Redox Biol 2016 April;7:78-87.

(18) Chucair AJ, Rotstein NP, Sangiovanni JP, During A, Chew EY, Politi LE. Lutein and zeaxanthin protect photoreceptors from apoptosis induced by oxidative stress: relation with docosahexaenoic acid. Invest Ophthalmol Vis Sci 2007 November;48(11):5168-77.

(19) Thornton J, Edwards R, Mitchell P, Harrison RA, Buchan I, Kelly SP. Smoking and age-related macular degeneration: a review of association. Eye (Lond) 2005 September;19(9):93544.

(20) Evans JR, Fletcher AE, Wormald RP. 28,000 Cases of age related macular degeneration causing visual loss in people aged 75 years and above in the United Kingdom may be attributable to smoking. $\mathrm{Br} \quad J$ Ophthalmol 2005 May;89(5):550-3.

(21) Tomany SC, Wang JJ, van LR et al. Risk factors for incident age-related macular degeneration: pooled findings from 3 continents. Ophthalmology 2004 July;111(7):1280-7.

(22) Espinosa-Heidmann DG, Suner IJ, Catanuto P, Hernandez EP, MarinCastano ME, Cousins SW. Cigarette smoke-related oxidants and the development of sub-RPE deposits in an experimental animal model of dry AMD. Invest Ophthalmol Vis Sci 2006 February;47(2):729-37.

(23) Imamura Y, Noda S, Hashizume K et al. Drusen, choroidal neovascularization, and retinal pigment epithelium dysfunction in SOD1-deficient mice: a model of age-related macular degeneration. Proc Natl Acad Sci U S A 2006 July 25;103(30):11282-7.

(24) Schutt F, Davies S, Kopitz J, Boulton M, Holz FG. [A retinoid constituent of lipofuscin, A2-E, is a photosensitizer in human retinal pigment epithelial cells]. Ophthalmologe 2000 October;97(10):682-7.

(25) Dontsov AE, Glickman RD, Ostrovsky MA. Retinal pigment epithelium pigment granules stimulate the photooxidation of unsaturated fatty acids. Free Radic Biol Med 1999 June;26(1112):1436-46.

(26) Rozanowska M, Sarna T. Light-induced damage to the retina: role of rhodopsin chromophore revisited. Photochem Photobiol 2005 November;81(6):130530.

(27) Rotstein NP, Politi LE, German OL, Girotti R. Protective effect of docosahexaenoic acid on oxidative stress-induced apoptosis of retina photoreceptors. Invest Ophthalmol Vis Sci 2003 May;44(5):2252-9.

(28) Subczynski WK, Wisniewska A, Widomska J. Location of macular xanthophylls in the most vulnerable regions of photoreceptor outer-segment membranes. Arch Biochem Biophys 2010 May 27.

(29) Bone RA, Landrum JT, Mayne ST, Gomez CM, Tibor SE, Twaroska EE. Macular pigment in donor eyes with and without AMD: a case-control study. Invest Ophthalmol Vis Sci 2001 January;42(1):235-40.

(30) Beatty S, Murray IJ, Henson DB, Carden D, Koh H, Boulton ME. Macular pigment and risk for age-related macular degeneration in subjects from a Northern European population. Invest Ophthalmol Vis Sci 2001 February;42(2):439-46. 


\section{NADPH Oxidase Activity in Retinal Pigmented Epithelium as a Target for Prevention of Age- related Macular Degeneration}

(31) Wustemeyer H, Jahn C, Nestler A, Barth T, Wolf S. A new instrument for the quantification of macular pigment density: first results in patients with AMD and healthy subjects. Graefes Arch Clin Exp Ophthalmol 2002 August;240(8):666-71.

(32) Miceli MV, Liles MR, Newsome DA. Evaluation of oxidative processes in human pigment epithelial cells associated with retinal outer segment phagocytosis. Exp Cell Res 1994 September;214(1):242-9.

(33) Tate DJ, Jr., Miceli MV, Newsome DA. Phagocytosis and $\mathrm{H} 2 \mathrm{O} 2$ induce catalase and metallothionein gene expression in human retinal pigment epithelial cells. Invest Ophthalmol Vis Sci 1995 June;36(7):1271-9.

(34) Li Q, Dinculescu A, Shan Z et al. Downregulation of p22phox in Retinal Pigment Epithelial Cells Inhibits Choroidal Neovascularization in Mice. Mol Ther 2008 July 29.

(35) Li Q, Dinculescu A, Shan Z et al. Downregulation of p22phox in retinal pigment epithelial cells inhibits choroidal neovascularization in mice. Mol Ther 2008 October;16(10):1688-94.

(36) Bhatt L, Groeger G, McDermott K, Cotter TG. Rod and cone photoreceptor cells produce ROS in response to stress in a live retinal explant system. $\mathrm{Mol}$ Vis 2010;16:283-93.

(37) Usui S, Oveson BC, Lee SY et al. NADPH oxidase plays a central role in cone cell death in retinitis pigmentosa. $J$ Neurochem 2009 August;110(3):102837.

(38) Velilla S, Garcia-Medina JJ, GarciaLayana A et al. Smoking and age-related macular degeneration: review and update. $\quad J \quad$ Ophthalmol 2013;2013:895147.

(39) Jaimes EA, DeMaster EG, Tian RX, Raij L. Stable compounds of cigarette smoke induce endothelial superoxide anion production via NADPH oxidase activation. Arterioscler Thromb Vasc Biol 2004 June;24(6):1031-6.

(40) Orosz Z, Csiszar A, Labinskyy N et al. Cigarette smoke-induced proinflammatory alterations in the endothelial phenotype: role of NAD(P)H oxidase activation. Am $J$ Physiol Heart Circ Physiol 2007 January;292(1):H130-H139.

(41) Asano H, Horinouchi T, Mai Y et al. Nicotine- and tar-free cigarette smoke induces cell damage through reactive oxygen species newly generated by PKC-dependent activation of NADPH oxidase. $J$ Pharmacol Sci 2012;118(2):275-87.

(42) Mai Y, Higashi $T$, Terada $K$ et al. Nicotine- and tar-free cigarette smoke extract induces cell injury via intracellular $\mathrm{Ca} 2+-$ dependent subtypespecific protein kinase $\mathrm{C}$ activation. $J$ Pharmacol Sci 2012;120(4):310-4.

(43) Noya Y, Seki K, Asano $H$ et al. Identification of stable cytotoxic factors in the gas phase extract of cigarette smoke and pharmacological characterization of their cytotoxicity. Toxicology 2013 December 6;314(1):110.

(44) Huang P, Wang F, Sah BK et al. Homocysteine and the risk of agerelated macular degeneration: a systematic review and meta-analysis. Sci Rep 2015;5:10585.

(45) Christen WG, Glynn RJ, Chew EY, Albert CM, Manson JE. Folic acid, pyridoxine, and cyanocobalamin combination treatment and age-related macular degeneration in women: the Women's Antioxidant and Folic Acid Cardiovascular Study. Arch Intern Med 2009 February 23;169(4):335-41.

(46) Siow YL, Au-Yeung KK, Woo CW, O K. Homocysteine stimulates 


\section{NADPH Oxidase Activity in Retinal Pigmented Epithelium as a Target for Prevention of Age- related Macular Degeneration}

phosphorylation of NADPH oxidase p47phox and p67phox subunits in monocytes via protein kinase Cbeta activation. Biochem J 2006 August 15;398(1):73-82.

(47) Signorello MG, Segantin A, Passalacqua M, Leoncini G. Homocysteine decreases platelet NO level via protein kinase C activation. Nitric Oxide 2009 March;20(2):104-13.

(48) Jakubowski H. Homocysteine thiolactone: metabolic origin and protein homocysteinylation in humans. $J$ Nutr 2000 February;130(2S Suppl):377S$81 \mathrm{~S}$.

(49) Huo Y, Li J, Qin X et al. Efficacy of folic acid therapy in primary prevention of stroke among adults with hypertension in China: the CSPPT randomized clinical trial. JAMA 2015 April 7;313(13):1325-35.

(50) Zhang C, Chi FL, Xie TH, Zhou YH. Effect of B-vitamin supplementation on stroke: a meta-analysis of randomized controlled trials. PLOS ONE 2013;8(11):e81577.

(51) Dong H, Pi F, Ding Z et al. Efficacy of Supplementation with B Vitamins for Stroke Prevention: A Network MetaAnalysis of Randomized Controlled Trials. PLoS ONE 2015;10(9):e0137533.

(52) Miller AA, Drummond GR, Schmidt $\mathrm{HH}$, Sobey CG. NADPH oxidase activity and function are profoundly greater in cerebral versus systemic arteries. Circ Res 2005 November 11;97(10):1055-62.

(53) Chen X, Rong SS, Xu Q et al. Diabetes mellitus and risk of age-related macular degeneration: a systematic review and meta-analysis. PLoS ONE 2014;9(9):e108196.

(54) Chiu CJ, Milton RC, Gensler G, Taylor A. Association between dietary glycemic index and age-related macular degeneration in nondiabetic participants in the Age-Related Eye Disease Study. Am J Clin Nutr 2007 July;86(1):180-8.

(55) Chiu CJ, Hubbard LD, Armstrong J et al. Dietary glycemic index and carbohydrate in relation to early agerelated macular degeneration. Am J Clin Nutr 2006 April;83(4):880-6.

(56) Li X, Cai Y, Wang YS et al. Hyperglycaemia exacerbates choroidal neovascularisation in mice via the oxidative stress-induced activation of STAT3 signalling in RPE cells. PLoS ONE 2012;7(10):e47600.

(57) Inoguchi T, Li P, Umeda F et al. High glucose level and free fatty acid stimulate reactive oxygen species production through protein kinase C-dependent activation of $\mathrm{NAD}(\mathrm{P}) \mathrm{H}$ oxidase in cultured vascular cells. Diabetes 2000 November;49(11):193945.

(58) Shao B, Bayraktutan U. Hyperglycaemia promotes human brain microvascular endothelial cell apoptosis via induction of protein kinase C-ssI and prooxidant enzyme NADPH oxidase. Redox Biol 2014;2:694-701.

(59) Shao B, Bayraktutan U. Hyperglycaemia promotes cerebral barrier dysfunction through activation of protein kinase C-beta. Diabetes Obes Metab 2013 November;15(11):993-9.

(60) Xia L, Wang H, Munk S et al. High glucose activates PKC-zeta and NADPH oxidase through autocrine TGF-beta1 signaling in mesangial cells. $A m \mathrm{~J}$ Physiol Renal Physiol 2008 December;295(6):F1705-F1714.

(61) Inoguchi $\mathrm{T}$, Sonta $\mathrm{T}$, Tsubouchi $\mathrm{H}$ et al. Protein kinase C-dependent increase in reactive oxygen species (ROS) production in vascular tissues of diabetes: role of vascular $\mathrm{NAD}(\mathrm{P}) \mathrm{H}$ oxidase. $J$ Am Soc Nephrol 2003 August;14(8 Suppl 3):S227-S232. 


\section{NADPH Oxidase Activity in Retinal Pigmented Epithelium as a Target for Prevention of Age- related Macular Degeneration}

(62) Sonta T, Inoguchi T, Tsubouchi H et al. Evidence for contribution of vascular $\mathrm{NAD}(\mathrm{P}) \mathrm{H}$ oxidase to increased oxidative stress in animal models of diabetes and obesity. Free Radic Biol Med 2004 July 1;37(1):115-23.

(63) Sasaki S, Inoguchi T. The role of oxidative stress in the pathogenesis of diabetic vascular complications. Diabetes Metab J 2012 August;36(4):255-61.

(64) Inoguchi T, Sasaki S, Kobayashi K, Takayanagi R, Yamada T. Relationship between Gilbert syndrome and prevalence of vascular complications in patients with diabetes. JAMA 2007 September 26;298(12):1398-400.

(65) Nawrot TS, Staessen JA, Roels HA et al. Cadmium exposure in the population: from health risks to strategies of prevention. Biometals 2010 October;23(5):769-82.

(66) Tellez-Plaza M, Jones MR, DominguezLucas A, Guallar E, Navas-Acien A. Cadmium exposure and clinical cardiovascular disease: a systematic review. Curr Atheroscler Rep 2013 October;15(10):356.

(67) Hartwig A. Cadmium and cancer. Met Ions Life Sci 2013;11:491-507.

(68) McCarty MF. Zinc and multi-mineral supplementation should mitigate the pathogenic impact of cadmium exposure. Med Hypotheses 2012 November;79(5):642-8.

(69) Engstrom KS, Vahter M, Johansson G et al. Chronic exposure to cadmium and arsenic strongly influences concentrations of 8-oxo-7,8-dihydro-2'deoxyguanosine in urine. Free Radic Biol Med 2010 May 1;48(9):1211-7.

(70) Kippler M, Hossain MB, Lindh C et al. Early life low-level cadmium exposure is positively associated with increased oxidative stress. Environ Res 2012 January;112:164-70.
(71) Huang HB, Chen GW, Wang CJ et al. Exposure to heavy metals and polycyclic aromatic hydrocarbons and DNA damage in taiwanese traffic conductors. Cancer Epidemiol Biomarkers Prev 2013 January;22(1):102-8.

(72) Nair AR, Degheselle O, Smeets K, Van KE, Cuypers A. Cadmium-Induced Pathologies: Where Is the Oxidative Balance Lost (or Not)? Int J Mol Sci 2013;14(3):6116-43.

(73) Souza V, Escobar MC, Bucio L, Hernandez E, Gomez-Quiroz LE, Gutierrez Ruiz MC. NADPH oxidase and ERK1/2 are involved in cadmium induced-STAT3 activation in HepG2 cells. Toxicol Lett 2009 June 22;187(3):180-6.

(74) Chen L, Xu B, Liu L et al. Cadmium induction of reactive oxygen species activates the mTOR pathway, leading to neuronal cell death. Free Radic Biol Med 2011 March 1;50(5):624-32.

(75) Martinez FK, Uribe Marin BC, Souza A, $\mathrm{V}$ et al. Hepatocytes display a compensatory survival response against cadmium toxicity by a mechanism mediated by EGFR and Src. Toxicol In Vitro 2013 April;27(3):1031-42.

(76) Nwokocha CR, Baker A, Douglas D, McCalla G, Nwokocha M, Brown PD. Apocynin Ameliorates CadmiumInduced Hypertension Through Elevation of Endothelium Nitric Oxide Synthase. Cardiovasc Toxicol 2013 May 24.

(77) Almenara CC, Broseghini-Filho GB, Vescovi MV et al. Chronic cadmium treatment promotes oxidative stress and endothelial damage in isolated rat aorta. PLoS ONE 2013;8(7):e68418.

(78) Mohammadi-Bardbori A, Rannug A. Arsenic, cadmium, mercury and nickel stimulate cell growth via NADPH 


\section{NADPH Oxidase Activity in Retinal Pigmented Epithelium as a Target for Prevention of Age- related Macular Degeneration}

oxidase activation. Chem Biol Interact 2014 November 10;224C:183-8.

(79) Erie JC, Good JA, Butz JA, Hodge DO, Pulido JS. Urinary cadmium and agerelated macular degeneration. Am $J$ Ophthalmol 2007

September;144(3):414-8.

(80) Junemann AG, Stopa P, Michalke B et al. Levels of aqueous humor trace elements in patients with non-exsudative age-related macular degeneration: a case-control study. PLOS ONE 2013;8(2):e56734.

(81) Wu EW, Schaumberg DA, Park SK. Environmental cadmium and lead exposures and age-related macular degeneration in U.S. adults: the National Health and Nutrition Examination Survey 2005 to 2008. Environ Res 2014 August;133:178-84.

(82) Kim EC, Cho E, Jee D. Association between blood cadmium level and agerelated macular degeneration in a representative Korean population. Invest Ophthalmol Vis Sci 2014 September;55(9):5702-10.

(83) Park SJ, Lee JH, Woo SJ, Kang SW, Park KH. Five heavy metallic elements and age-related macular degeneration: Korean National Health and Nutrition Examination Survey, 2008-2011. Ophthalmology 2015 January;122(1):129-37.

(84) Kim MH, Zhao D, Cho J, Guallar E. Cadmium exposure and age-related macular degeneration. $J$ Expo Sci Environ Epidemiol 2016 March;26(2):214-8.

(85) A randomized, placebo-controlled, clinical trial of high-dose supplementation with vitamins $\mathrm{C}$ and $\mathrm{E}$, beta carotene, and zinc for age-related macular degeneration and vision loss: AREDS report no. 8. Arch Ophthalmol 2001 October;119(10):1417-36.
(86) Clemons TE, Kurinij N, Sperduto RD. Associations of mortality with ocular disorders and an intervention of highdose antioxidants and zinc in the AgeRelated Eye Disease Study: AREDS Report No. 13. Arch Ophthalmol 2004 May;122(5):716-26.

(87) Thurman JM, Renner B, Kunchithapautham $\mathrm{K}$ et al. Oxidative stress renders retinal pigment epithelial cells susceptible to complementmediated injury. J Biol Chem 2009 June 19;284(25):16939-47.

(88) Cortright DN, Meade R, Waters SM, Chenard BL, Krause JE. C5a, but not C3a, increases VEGF secretion in ARPE-19 human retinal pigment epithelial cells. Curr Eye Res 2009 January;34(1):57-61.

(89) Torres M, Forman HJ. Activation of several MAP kinases upon stimulation of rat alveolar macrophages: role of the NADPH oxidase. Arch Biochem Biophys 1999 June 15;366(2):231-9.

(90) Kato M, Yamaguchi T, Tachibana A et al. An atypical protein kinase C, PKC zeta, regulates human eosinophil effector functions. Immunology 2005 October;116(2):193-202.

(91) DiScipio RG, Schraufstatter IU, Sikora L, Zuraw BL, Sriramarao P. C5a mediates secretion and activation of matrix metalloproteinase 9 from human eosinophils and neutrophils. Int Immunopharmacol 2006 July;6(7):110918.

(92) Daniel DS, Dai G, Singh CR et al. The reduced bactericidal function of complement C5-deficient murine macrophages is associated with defects in the synthesis and delivery of reactive oxygen radicals to mycobacterial phagosomes. J Immunol 2006 October 1;177(7):4688-98.

(93) Chen $Y$, Okano K, Maeda $\mathrm{T}$ et al. Mechanism of all-trans-retinal toxicity 


\section{NADPH Oxidase Activity in Retinal Pigmented Epithelium as a Target for Prevention of Age- related Macular Degeneration}

with implications for stargardt disease and age-related macular degeneration. $J$ Biol Chem 2012 February 10;287(7):5059-69.

(94) Li J, Cai X, Xia Q et al. Involvement of endoplasmic reticulum stress in alltrans-retinal-induced retinal pigment epithelium degeneration. Toxicol Sci 2015 January;143(1):196-208.

(95) Zhu X, Wang K, Zhang K, Zhou F, Zhu L. Induction of oxidative and nitrosative stresses in human retinal pigment epithelial cells by all-trans-retinal. Exp Cell Res 2016 October 15;348(1):87-94.

(96) Haruta M, Bush RA, Kjellstrom S et al. Depleting Rac1 in mouse rod photoreceptors protects them from photo-oxidative stress without affecting their structure or function. Proc Natl Acad Sci $U$ S A 2009 June 9;106(23):9397-402.

(97) Allikmets R. Further evidence for an association of ABCR alleles with agerelated macular degeneration. The International ABCR Screening Consortium. Am J Hum Genet 2000 August;67(2):487-91.

(98) Carrizzo A, Forte $M$, Lembo $M$, Formisano L, Puca AA, Vecchione C. Rac-1 as a new therapeutic target in cerebro- and cardio-vascular diseases. Curr Drug Targets 2014;15(13):123146.

(99) Hong H, Zeng JS, Kreulen DL, Kaufman DI, Chen AF. Atorvastatin protects against cerebral infarction via inhibition of NADPH oxidase-derived superoxide in ischemic stroke. Am J Physiol Heart Circ Physiol 2006 November;291(5):H2210-H2215.

(100) Wagner AH, Kohler T, Ruckschloss U, Just I, Hecker M. Improvement of nitric oxide-dependent vasodilatation by HMG-CoA reductase inhibitors through attenuation of endothelial superoxide anion formation. Arterioscler Thromb Vasc Biol 2000 January;20(1):61-9.

(101) Whaley-Connell A, Habibi J, Nistala R et al. Attenuation of NADPH oxidase activation and glomerular filtration barrier remodeling with statin treatment. Hypertension 2008 February;51(2):47480.

(102) Al-Holou SN, Tucker WR, Agron E et al. The Association of Statin Use with Age-Related Macular Degeneration Progression: The Age-Related Eye Disease Study 2 Report Number 9. Ophthalmology 2015 December;122(12):2490-6.

(103) Gehlbach P, Li T, Hatef E. Statins for age-related macular degeneration. Cochrane Database Syst Rev 2015;2:CD006927.

(104) Barbosa DT, Mendes TS, Cintron-Colon $\mathrm{HR}$ et al. Age-related macular degeneration and protective effect of HMG Co-A reductase inhibitors (statins): results from the National Health and Nutrition Examination Survey 2005-2008. Eye (Lond) 2014 April;28(4):472-80.

(105) Vavvas DG, Daniels AB, Kapsala ZG et al. Regression of Some High-risk Features of Age-related Macular Degeneration (AMD) in Patients Receiving Intensive Statin Treatment. EBioMedicine 2016 March;5:198-203.

(106) Lanone S, Bloc S, Foresti R et al. Bilirubin decreases nos2 expression via inhibition of $\mathrm{NAD}(\mathrm{P}) \mathrm{H}$ oxidase: implications for protection against endotoxic shock in rats. FASEB J 2005 November;19(13):1890-2.

(107) Matsumoto $\mathrm{H}$, Ishikawa $\mathrm{K}$, Itabe $\mathrm{H}$, Maruyama Y. Carbon monoxide and bilirubin from heme oxygenase-1 suppresses reactive oxygen species generation and plasminogen activator inhibitor-1 induction. Mol Cell Biochem 2006 October;291(1-2):21-8. 


\section{NADPH Oxidase Activity in Retinal Pigmented Epithelium as a Target for Prevention of Age- related Macular Degeneration}

(108) Jiang F, Roberts SJ, Datla S, Dusting GJ. NO modulates NADPH oxidase function via heme oxygenase-1 in human endothelial cells. Hypertension 2006 November;48(5):950-7.

(109) McCarty MF. Clinical potential of Spirulina as a source of phycocyanobilin. J Med Food 2007 December;10(4):566-70.

(110) Zheng J, Inoguchi T, Sasaki S et al. Phycocyanin and phycocyanobilin from Spirulina platensis protect against diabetic nephropathy by inhibiting oxidative stress. Am J Physiol Regul Integr Comp Physiol 2013 January 15;304(2):R110-R120.

(111) Chamorro G, Perez-Albiter M, SerranoGarcia N, Mares-Samano JJ, Rojas P. Spirulina maxima pretreatment partially protects against 1-methyl-4-phenyl1,2,3,6-tetrahydropyridine neurotoxicity. Nutr Neurosci 2006 October;9(5-6):20712.

(112) Rimbau V, Camins A, Romay C, Gonzalez R, Pallas M. Protective effects of C-phycocyanin against kainic acidinduced neuronal damage in rat hippocampus. Neurosci Lett 1999 December 3;276(2):75-8.

(113) Penton-Rol G, Marin-Prida J, PardoAndreu $G$ et al. C-Phycocyanin is neuroprotective against global cerebral ischemia/reperfusion injury in gerbils. Brain Res Bull 2011 August 10;86(12):42-52.

(114) Marin-Prida J, Pavon-Fuentes N, Llopiz-Arzuaga A et al. Phycocyanobilin promotes PC12 cell survival and modulates immune and inflammatory genes and oxidative stress markers in acute cerebral hypoperfusion in rats. Toxicol Appl Pharmacol 2013 October 1;272(1):49-60.

(115) Lin JP, Vitek L, Schwertner HA. Serum Bilirubin and Genes Controlling Bilirubin Concentrations as Biomarkers for Cardiovascular Disease. Clin Chem 2010 August 6. 